\title{
BASTIDORES DA INCLUSÃO: A RELAÇÃO EDUCACIONAL PROFESSOR - ALUNO SURDO - INTÉRPRETE DE LIBRAS ${ }^{28}$ \\ FRAMES OF INCLUSION: THE EDUCATIONAL RELATIONSHIP TEACHER- DEAF STUDENT - INTERPRETER OF LIBRAS
}

Ester Vitória Basilio Anchieta 29

\begin{abstract}
Resumo
Este estudo foi realizado em uma escola pública e tem como objetivo promover reflexões sobre práticas educacionais inclusivas com surdos. É inegável que a educação se encontra perante um encontro muito particular entre dois profissionais atuantes diretamente na educação dos surdos: professores e intérpretes. Mas, no contexto inclusivo existem, na verdade, três personagens: alunos surdos, intérprete de Libras e professor. Não há dúvida de que o surdo é protagonista nessa relação tripartite. O mesmo não se pode dizer concernente à prática educacional em sala de aula, cuja eficácia é questionada por revelar ausência de respostas concretas para problemas de aprendizado desses sujeitos, mostrando aspectos negligenciados que precisam ser discutidos, os quais deram corpo a este texto.
\end{abstract}

Palavras-chave: Relação educacional. Inclusão. Aluno surdo.

\section{Abstract}

This study was carried out in a public school and aims to promote reflections on inclusive educational practices with the deaf. It is undeniable that education is faced by a very particular duel between two professionals directly involved in the education of the deaf: teachers and interpreters. But in the inclusive context there are, in fact, three characters: deaf students, interpreter of Libras and teacher. There is no doubt that the deaf is the protagonist in this tripartite relationship. The same can not be said about classroom educational practice, whose effectiveness is questioned because it reveals the absence of concrete answers to learning problems of these subjects, showing neglected aspects that need to be discussed, which gave substance to this text.

Keywords: Educational relationship. Inclusion. Deaf student.

\footnotetext{
${ }^{28}$ Este estudo foi feito a partir de um recorte da dissertação de Mestrado da autora.

${ }^{29}$ Professora na Universidade Estadual do Rio de Janeiro (FEBF/UERJ). Doutoranda no Programa de Pós Graduação em Educação da UERJ (PropEd/UERJ). E-mail: estervbasilio@gmail.com
} 


\section{RevistAleph}

\section{Introdução}

No panorama atual, os sujeitos surdos têm sido respaldados por leis, como o Decreto no 5626/2005, que é regulamentador de um outro dispositivo norteador, a Lei $n^{\circ}$ 10.436/2002. Grande conquista para a comunidade surda, essa lei reconhece a Libras (Língua Brasileira de Sinais) como meio legal de comunicação e expressão desses sujeitos.

O decreto citado esclarece que a educação dos surdos deverá ser realizada em língua de sinais enquanto a modalidade escrita deverá ser em português, em um plano de segunda língua. Toda conquista legal vem tomando espaço e melhorando no quesito aceitação. Para cumprirem um viés de inclusão, as escolas têm se "acessibilizado", através de tradutores intérpretes de Libras/português, para promover a comunicação entre surdos e ouvintes.

De acordo com Fernandes (2006), ao nos depararmos com todas as mudanças que refletem diretamente na sala de aula, abre-se uma nova discussão acerca do ensino das pessoas com surdez, a qual repousa sobre a proposta de uma educação bilíngue.

O Bilinguismo defende a disponibilidade de duas línguas dentro da escola: a língua de sinais e a língua de modalidade oral/auditiva. Essa diretriz alega que a estratégia de ensinar Libras como Primeira Língua (L1) e português como Segunda Língua (L2) promoverá a valorização da língua de sinais aos sujeitos que a dominam e ainda fornecerá o ensino do português de forma adequada.

No horizonte dos últimos 12 anos, a partir do momento em que surgiu a Lei $\mathrm{n}^{\circ}$ $10.436 / 2002$, as salas de aula deveriam ganhar um novo cenário que passou a acomodar dois profissionais: o professor e o intérprete. Não tanto quanto a proposta da Libras como L1, este foi um grande marco na história de educação de surdos.

Nesse cenário escolar inclusivo, com salas de aula que mesclam alunos surdos e ouvintes, ensinados por professores restritamente ouvintes, mas que contam com a ajuda de um profissional TILS ${ }^{30}$, insere-se a pesquisa em questão. O objetivo foi traçar como se dá a relação entre alunos surdos, professores e intérpretes e de trazer às claras o real sentimento de todos os envolvidos no quadro de inclusão.

O contexto em que há uma valorização e defesa de salas bilíngues, onde a LIBRAS é vista como L1, incluindo professores surdos que ministram as aulas em sinais, sugere

${ }^{30}$ Tradutor/intérprete de língua(s) de sinais. 


\section{RevistAleph}

críticas à proposta inclusiva. Assim posto, a hipótese da pesquisa, realizada em uma escola inteiramente inclusiva, era de encontrar uma insatisfação dos surdos em relação à presença de TILS (Tradutores intérpretes de língua de sinais) em sala de aula, haja vista defenderem uma educação integralmente bilíngue. O resultado foi surpreendente, como será discutido nas próximas seções.

A escola investigada, Escola Municipal Oswaldo Velloso, está localizada na cidade de Juiz de Fora/MG e contou com o maior número de surdos no ano de 2014. Consequentemente, este foi o período de maior contratação de TILS ${ }^{31}$. É importante frisar que os professores desta escola são todos ouvintes. Segundo Carvalho e Barbosa (2008), agregar surdos e ouvintes em um ambiente de coparticipação é essencial para que o processo de inclusão aconteça, pois assim estarão sendo respeitadas e aceitas as diferenças individuais.

Com o intuito de entender este ambiente de coparticipação e seus impactos na educação para surdos, a metodologia da pesquisa incluiu visitas na escola e aplicação de três questionários distintos, um para alunos surdos, outro para professores e outro para TILS. Acredita-se que os dados levantados por meio dos questionários suscitarão novas questões reflexivas que implicarão na qualidade de ensino à pessoa com surdez.

\section{A pesquisa}

Além de promover reflexões acerca de práticas educacionais, a pesquisa apresentada pleiteia dados que contribuam com projetos para uma escola bilíngue para surdos em Juiz de Fora/MG.

Tendo em vista que os respaldos legais atuais asseguram que toda escola deve ter seus espaços totalmente adaptados a receber qualquer aluno, a pergunta é: e quando se trata de uma diferença linguística, qual os meios de acessibilidade pensados pela instituição?

A discussão aqui travada considera a língua de sinais como primeira língua das pessoas surdas, ou seja, como sua língua materna. Segundo as teorias de Noam Chomsky e de outros estudiosos linguistas, a língua materna pode ser entendida como aquela em

\footnotetext{
31 Decerto, ainda há uma longa discussão que pode ser feita a respeito da contratação de apenas um intérprete de Libras, considerando que o cansaço físico e mental, após tantas horas de trabalho, poderá comprometer a qualidade da tradução. Todavia, não adentraremos neste mérito, mas discutiremos alguns pontos resultantes desta ação, ou melhor, a falta dela.
} 


\section{RevistAleph}

que há um conforto maior para a comunicação, aquela que se domina melhor em termos argumentativos e expressivos; ou pode ser vista também como aquela que se dá naturalmente, sendo a língua nativa do indivíduo.

No âmbito da surdez, reconhecendo-se a ausência do canal auditivo, não há dúvida que a comunicação torna-se melhor através de uma modalidade gesto/visual. Por isso, a comunidade surda, muitas vezes, tem se posicionado contrária às classes nomeadas inclusivas, onde há surdos e ouvintes juntos, e se colocado a favor do fortalecimento e da implementação de escolas bilíngues para surdos, com salas em que as disciplinas sejam lecionadas em Libras, com o português somente na modalidade escrita.

Acredita-se que, desta forma, a língua contribuirá no processo de ensinoaprendizagem e não mais atuará como algo que perpassa pelo mediador, neste caso o TILS. Na escola pesquisada não seria diferente. A defesa e luta por uma escola bilíngue trazem suas marcas. Tais dados podem ser comprovados mais adiante.

O projeto de educação bilíngue em Juiz de Fora/MG é uma iniciativa já tardia em relação a outros estados do país. Na Escola Municipal Oswaldo Velloso ele tem o objetivo de contemplar uma educação integralmente acessível à pessoa com surdez. Em razão de ter como L1 a Libras, pode-se dizer que a presença do intérprete de Libras é discutível. A respeito da educação para surdos Frias (2010, apud GONÇALVES; FESTA, 2013, p. 2) diz que:

[...] a inclusão dos alunos com surdez na escola regular deve contemplar mudanças no sistema educacional e uma adaptação no currículo, com alterações nas formas de ensino, metodologias adequadas e avaliação que condiz com as necessidades do aluno Surdo; requer também elaboração de trabalhos que promovam à interação em grupos na sala de aula e espaço físico adequado a circulação de todos. A inclusão deve ocorrer, ainda que existam desafios, com garantia de oportunidades ao aluno surdos iguais aos do aluno ouvinte.

É fato que a presença de qualquer aluno que demande algum tipo de adaptação requer do professor o reconhecimento da necessidade de adaptação curricular e metodológica. No caso do aluno surdo, é evidente a necessidade de atitudes docentes condizentes com o perfil assumido pela classe ao ter incluído esse aluno. Dito isto, a pesquisa em tela adentra nos seguintes pontos referentes à postura docente: formas e posturas de avaliação; adaptação de metodologias; presença ou ausência na educação dos 


\section{RevistAleph}

surdos; transferência de papéis (professor/intérprete); e bem-estar ou mal-estar em relação aos alunos surdos e TILS.

Sabendo-se que neste contexto a presença do TILS também é crucial, buscou-se saber principalmente se assumem o papel designado ao professor, bem como as ações que norteiam sua postura ética, sua formação acadêmica e suas perspectivas para com os sujeitos surdos com quem lidam diariamente.

Já no que concerne aos principais sujeitos motivadores desta pesquisa - os alunos surdos -, a análise teve seu foco no bem-estar ou mal-estar desses sujeitos dentro de uma escola onde a língua predominante é de modalidade oral. Além disso, deu atenção à importância dos profissionais que atuam em seu favor e às relações que estabelecem com eles. Para dar continuidade à discussão é necessário, portanto, destacar como a palavra "relação" é entendida. Segundo o dicionário:

[...] relação re.la.ção sf (lat relatione) 1 Conexão entre dois objetos, fenômenos ou quantidades, tal que a modificação de um deles importa na modificação do outro. 2 Ligação íntima de coisas ou pessoas. [...] $\boldsymbol{R}$. humanas: a) comportamento do indivíduo em seus contatos de pessoa a pessoa, de pessoa a grupo ou de pessoa a sociedade; b) observância de um conjunto de princípios na esfera dos contatos pessoais, visando a um perfeito entendimento entre chefes e subordinados, nas empresas.

As relações que acontecem dentro de uma sala de aula não podem ser ditadas. Falar de relações interpessoais é colocar em jogo tudo que se passa dentro dos indivíduos e é ou não externado em alguma circunstância. Freire (1987) já dizia que em uma prática educacional é preciso considerar a "bagagem" inerente do próprio aluno.

Partindo então do pressuposto de que num contexto escolar normalmente há heterogeneidade, buscou-se refletir sobre o funcionamento do processo de ensinoaprendizagem e das relações estabelecidas em sala, considerando, além da "bagagem" do professor, a bagagem de um profissional a mais e a do indivíduo surdo, integrante e ativo em uma comunidade repleta de marcas históricas, militâncias e de cultura singular.

\section{Metodologia de pesquisa}

O viés metodológico usado nesta pesquisa foi a análise de dados, os quais foram levantados mediante entrevistas direcionadas a alunos surdos, intérpretes e professores de uma única escola, localizada no centro da cidade de Juiz de Fora/MG. Foram 


\section{RevistAleph}

formulados três (3) questionários distintos, um para cada personagem. Em cinco (5) visitas à escola, foram localizados dez (10) alunos surdos, dez (10) professores que atuam com surdos e três (3) intérpretes. É importante ressaltar que a escola possui, em sua totalidade, a média de dois mil alunos, sendo doze deles (12) surdos.

Cada questionário foi composto, em média, por quarenta (40) questões objetivas e duas (2) discursivas optativas, estas últimas de caráter complementar, sendo respondidas a critério dos entrevistados. Havia no questionário a opção de anonimato e, mesmo não sendo a opção de todos, para melhor produção da análise desta pesquisa e para se preservar a identidade dos participantes, não serão usados os nomes dos sujeitos. A opção de anonimato foi escolhida por quatro (4) pessoas, sendo duas (2) surdas e dois (2) professores.

Tabela 1 - Descrição dos questionários

\begin{tabular}{|c|c|c|c|}
\hline & Objetivos principais dos questionários & $\begin{array}{l}\text { Quantidade de } \\
\text { entrevistados }\end{array}$ & $\begin{array}{l}\text { Número de } \\
\text { questões }\end{array}$ \\
\hline Professores & $\begin{array}{l}\text { *Formas e posturas de avaliação } \\
\text { *Adaptação de metodologias } \\
\text { *Presença ou ausência dos docentes na educação dos surdos } \\
\text { *Transferência de papéis (Professor/intérprete) } \\
\text { *Bem-estar ou mal-estar docente em relação aos alunos surdos } \\
\text { e TILS }\end{array}$ & 10 & 40 \\
\hline Intérpretes & $\begin{array}{l}\text { *Se estes profissionais assumem o papel designado ao } \\
\text { professor } \\
\text { *Ações que norteiam sua postura ética } \\
\text { *Formação acadêmica } \\
\text { *Perspectiva sobre os sujeitos surdos que lidam diariamente }\end{array}$ & 3 & 42 \\
\hline $\begin{array}{l}\text { Alunos } \\
\text { Surdos }\end{array}$ & $\begin{array}{l}\text { *Bem-estar ou mal-estar dentro de uma escola onde a língua } \\
\text { predominante é de modalidade oral } \\
\text { *Perspectiva sobre importância dos profissionais que atuam } \\
\text { juntos } \\
\text { * Relações com os profissionais. }\end{array}$ & 10 & 38 \\
\hline Total: & & 23 & 120 \\
\hline
\end{tabular}

Fonte: Elaborada pela autora.

A entrevista feita aos sujeitos surdos foi coletiva e traduzida para Libras. Quatro (4) surdos são alunos do 10 ano do ensino médio, três (3) do segundo ano do ensino médio e os outros três (3) do terceiro ano do ensino médio, conforme demonstrado na tabela explicativa abaixo: 


\section{RevistAleph}

Tabela 2-Quantidade de surdos por séries

\begin{tabular}{|l|l|}
\hline Série & Quantidade de alunos surdos \\
\hline $1^{\circ}$ ano do E.M. & 4 \\
\hline $2^{\circ}$ ano do E.M. & 3 \\
\hline $3^{\circ}$ ano do E.M. & 3 \\
\hline
\end{tabular}

Fonte: Elaborada pela autora.

\section{Levantamento de dados}

As hipóteses para a pesquisa consistiam, basicamente, em encontrar uma rejeição da parte dos surdos pelas escolas inclusivas e uma não-aceitação pelo fechamento de escolas de ensino regular. Esperava-se também um quadro de professores despreparados e não conhecedores dos aspectos da surdez, além de intérpretes de LS apenas certificados e não formados/preparados para exercerem a profissão.

A pesquisa não sofreu barreiras para sua execução. A aceitação dos sujeitos para o preenchimento dos questionários, a abertura da escola e a receptividade dos alunos e funcionários foi esplêndida. Os 10 professores entrevistados atuam no ensino médio, sendo cinco (5) do gênero feminino e cinco (5) do gênero masculino. Cinquenta por cento (50 \%) dos professores possuem entre um (1) e cinco (5) anos de contato com alunos surdos e os outros cinquenta por cento (50 \%) entre cinco (5) e dez (10) anos (Conforme indicado no gráfico 1). 


\section{RevistAleph}

\section{Gráfico 1 - Tempo de atuação dos professores com alunos surdos}

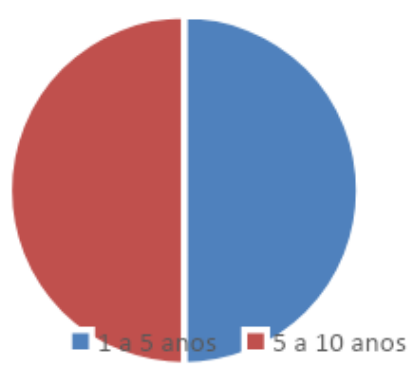

Fonte: Elaborado pela autora.

No que se refere à forma e postura de avaliação, cinquenta por cento (50\%) dos professores têm procurado adaptar a prova utilizando mais imagens. Além disso, passaram a solicitar ajuda dos TILS aos surdos durante a execução da avaliação (Dados indicados no gráfico 2), questão que será tratada mais à frente.

\section{Gráfico 2- Professores que adaptam as provas para os} alunos surdos

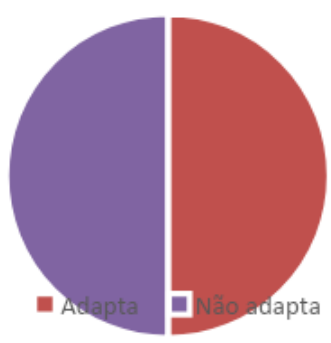

Fonte: Elaborado pela autora.

Os dez (10) professores entrevistados relataram ter problema com alunos surdos "copistas" (Dado indicado no gráfico 3) e que sentem necessidade de cursos de formação continuada para que possam melhor atender este cenário. 


\section{RevistAleph}

\section{Gráfico 3- Professores que enfrentam dificuldades com alunos surdos}

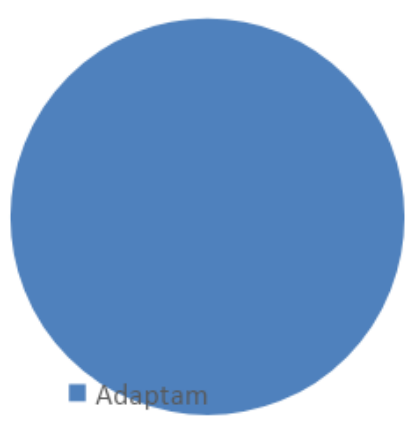

Fonte: Elaborado pela autora.

Em 100\% das questões referentes ao debate sobre escolas inclusivas $x$ especiais, todos os professores defenderam a escola inclusiva como aquela que oferece melhor acesso à pessoa com surdez (Dados indicados no gráfico 4).

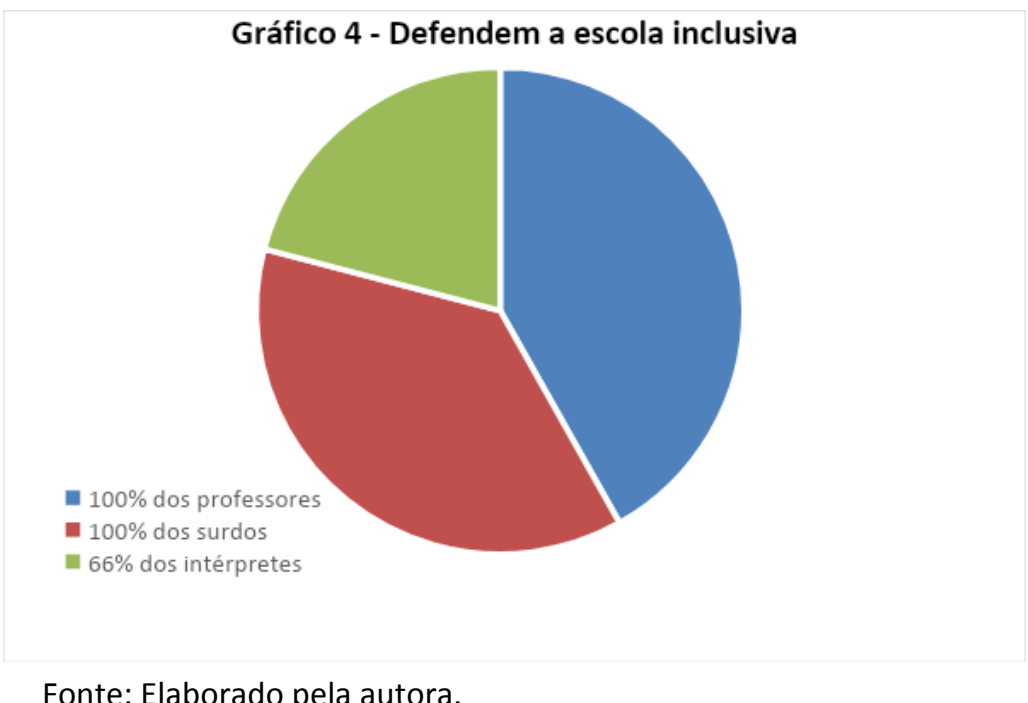

Fonte: Elaborado pela autora.

Os professores, unanimamente, demonstraram satisfação com a presença dos TILS dentro de sala de aula. Não se queixaram de nenhuma prática e ainda relataram que sem os intérpretes as aulas para surdos não aconteceriam, pois nenhum dos professores entrevistados é fluente na LSB, sendo apenas três (3) deles comunicadores básicos. A relação professor-intérprete pareceu ser agradável e ausente de contendas e problemas.

Os três (3) TILS abordados para este trabalho são graduados em Pedagogia, mas aprenderam Libras em cursos livres e em contato com surdos, com exceção de um 1 deles, o único do gênero masculino e filho de pais surdos, o que o faz um CODA (Childrens of 


\section{RevistAleph}

Deaf Adults $^{32}$ ). Importante ressaltar também que uma das Tradutoras intérpretes é pósgraduanda em Libras. $O$ gráfico 5 indica o tempo de atuação dos TILS.

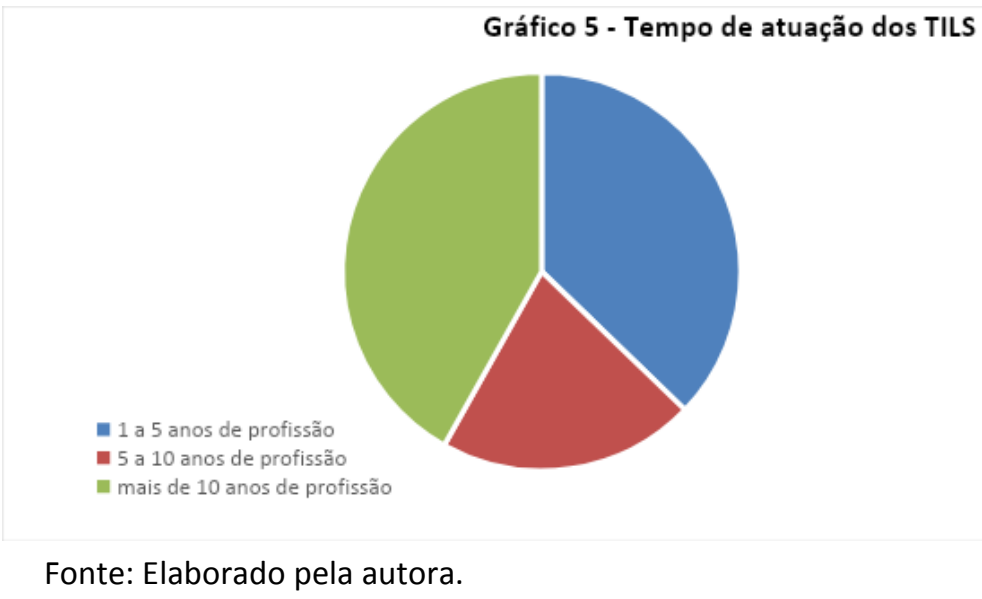

Os questionários traziam perguntas específicas sobre as formas de avaliação. Foi indagado, por exemplo, se os TILS acompanhavam o aluno durante as provas avaliativas e todos responderam que sim. Foi questionado ainda aos intérpretes se os professores lhes passavam os materiais das aulas com antecedência. As respostas oscilaram. Alguns disseram que sim e outros que não.

Um dos pontos interessantes observado foi a falta de reciprocidade de satisfação dos profissionais no que se refere à relação intérprete-professor. Enquanto a maioria dos professores revelou satisfação quanto ao trabalho com os TILS, $100 \%$ destes demonstraram alguma insatisfação quanto aos professores. Eles reclamaram da falta de acessibilidade em provas e a materiais, dizendo que, para muitos professores, a presença do intérprete já garante a acessibilidade aos alunos surdos. Os próprios TILS, entretanto, admitiram que seria necessária uma tradução prévia das avaliações. Sobre a relação entre esses profissionais seguem os gráficos explicativos 6 e 7 :

\footnotetext{
32 “Nos anos 80, o acrônimo Coda (Child of Deaf Adults) ganhou popularidade, sobretudo pela fundação da organização internacional Children of Deaf Adults, Inc (CODA) que, sediada nos EUA, dedica-se à promoção de temas relacionados às experiências de filhos ouvintes de pais surdos, mundo afora". Disponível em: https://culturasurda.net/2013/02/01/coda/.
} 


\section{RevistAleph}

Gráfico 6 - Satisfação dos Professores em relação aos

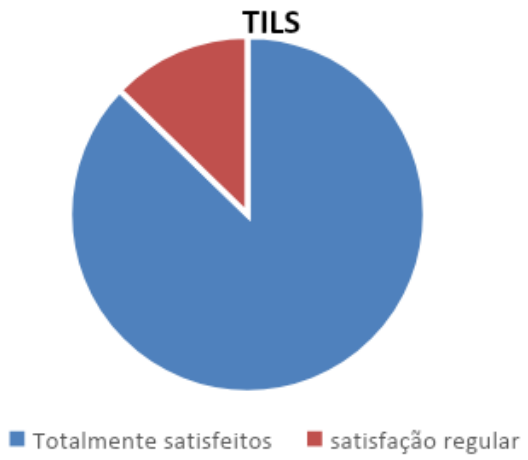

Fonte: Elaborado pela autora.

Gráfico 7 - Satisfação dos Professores em relação aos TILS

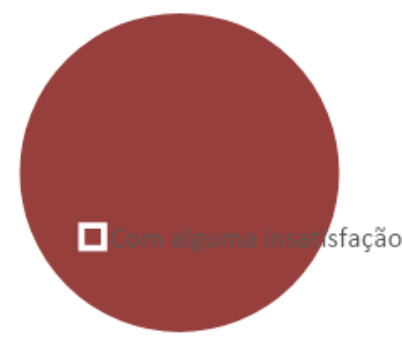

Fonte: Elaborado pela autora.

Em sua relação com os alunos surdos, os TILS demonstraram total companheirismo, ética profissional e parcialidade. Não se queixaram de comportamentos inadequados ou confusões de papéis entre Intérpretes e professores. Os alunos, em sua integralidade, procuram sempre os professores em caso de dúvidas, solicitando a adaptação de materiais como filmes, textos e afins.

Os TILS se demonstraram solícitos aos surdos presentes na comunidade e atuantes em sua busca por formação, levando em consideração as limitações de ofertas até o ano de 2013 na cidade. 100\% dos TILS entrevistados pretendem ingressar no curso de Letras Libras da Universidade Federal de Juiz de Fora tão logo seja aberta a modalidade de bacharelado. Eles reconhecem, pois, a importância que a formação pode trazer ao seu desempenho profissional. 


\section{RevistAleph}

\section{Análise dos dados}

Diante dos dados coletados, é possível salientar que a educação encontra-se numa confluência de dois profissionais que atuam diretamente com a educação dos surdos: professores e TILS. No contexto que mescla surdos e ouvintes, nomeado inclusivo, fomenta-se as indagações que despertaram esta pesquisa: como o conhecimento tem caminhado até os sujeitos surdos?

Além da reflexão sobre as formas como a língua passa pelo processo tradutório, é importante pensar: será que esse método garante integralmente a melhor formação para o aluno? Como os próprios alunos surdos lidam com essa situação? Será que se sentem com seus direitos garantidos por lei? Quem é a referência do aluno? Sobre o ponto de vista profissional, quais estratégias de ensino e socialização têm sido promovidas? Qual tem sido a postura do Tradutor Intérprete de Língua de sinais? O aluno tem acesso direto ao professor? $O$ intérprete tem mediado algo além da língua? Como funciona o trabalho de dois profissionais na mesma sala de aula?

$\mathrm{Na}$ investigação inicial a relação pedagógica entre professor, intérprete de Libras e aluno surdo causou inquietação. Muitas dúvidas sobre essas relações surgiram, mas principalmente sobre o sentimento de cada um desses personagens. Será que os professores conhecem a surdez? O que conhecem? Quais as dificuldades e desafios? Como se conduz a interação? Como se procede a adaptação curricular? Tem acontecido a inclusão ou a exclusão?

Pode-se dizer que os dados levantados com esta pesquisa contribuem para uma rica reflexão acerca destas práticas. De início, é importante pensar sobre os TILS. A exigência do tradutor e intérprete de Libras em sala de aula, como já foi dito, se deu em 2005. Por se tratar de um profissional novo no contexto educacional, é possível observar muitos conflitos para uma compreensão clara do seu papel. Alguns professores esclareceram que a presença do TILS "alivia" sua preocupação com o grupo de alunos surdos, deixando por conta deles qualquer tipo de correção e repreensão, motivo este de, como apontam os dados obtidos na pesquisa, não haver a reciprocidade dos TILS para com os professores.

Em se tratando da relação desse profissional com os alunos, no decorrer da pesquisa observou-se que um (1) aluno surdo não sabia a Língua de Sinais e se 


\title{
RevistAleph
}

demonstrou defensor da imposição oralista e da "ouvintização" vivida no século passado. Sobre os TILS, este aluno não compreendia que se tratava de um colaborador da instituição na qual estava inserido. Porém, os demais alunos revelaram uma total aceitação e apoio à profissão, sem problemas de afinidade ou mal-estar.

Sabemos que este recorte de pesquisa é muito pequeno para a grandeza das especificidades que surgem nas relações aqui analisadas. Mesmo assim, foi possível observar que pode ocorrer uma afinidade entre o intérprete e o aluno surdo.

\begin{abstract}
O intérprete especialista para atuar na área da educação deverá ter um perfil para intermediar as relações entre os professores e os alunos, bem como, entre os colegas surdos e os colegas ouvintes. No entanto, as competências e responsabilidades destes profissionais não são tão fáceis de serem determinadas. Há vários problemas de ordem ética que acabam surgindo em função do tipo de intermediação que acaba acontecendo em sala de aula. Muitas vezes, o papel do intérprete em sala de aula acaba sendo confundindo com o papel do professor. Os alunos dirigem questões diretamente ao intérprete, comentam e travam discussões em relação aos tópicos abordados com o intérprete e não com o professor (QUADROS, 2004, p. 60).
\end{abstract}

Essa aproximação entre esses dois sujeitos é fortificada pela rotina. O intérprete está diariamente em contato com o aluno surdo, participando de todas as aulas e atividades em que está inserido. É claro que nessa relação poderá surgir conflitos. Também é comum relatos de que alguns alunos surdos se afeiçoam intensamente aos intérpretes produzindo, assim, situações até mesmo constrangedoras de ciúmes. Há instituições que, para evitar esse laço, fazem rodízios semestrais dos profissionais nas turmas para não estabelecer a possibilidade de algum conflito ético e/ou pessoal.

Muitos intérpretes convivem com a comunidade surda e isso é bom, pois, é dessa forma que se aprendem novos sinais e não se perde a fluência na língua. Uma questão que costuma ocorrer é que o surdo, ao ingressar em alguma instituição, tem como intérprete um amigo que conheceu fora desse ambiente, o que conflita a postura destes personagens frente à relação restritamente profissional.

Quando se fala dessas relações com o docente, é necessário entender que muitos professores, quando se deparam com uma situação com a qual não estão acostumados, têm a tendência de fugir ou transmitir a responsabilidade para outra pessoa. Um professor que nunca teve a oportunidade de ter contato com pessoas com deficiência e, no caso, com um surdo, sente-se despreparado para exercer o seu papel. 


\section{RevistAleph}

O próprio professor delega ao intérprete a responsabilidade de assumir o ensino dos conteúdos desenvolvidos em aula ao intérprete. Muitas vezes, o professor consulta o intérprete a respeito do desenvolvimento do aluno surdo, como sendo ele a pessoa mais indicada a dar um parecer a respeito. O intérprete, por sua vez, se assumir todos os papéis delegados por parte dos professores e alunos, acaba sendo sobrecarregado e, também, acaba por confundir o seu papel dentro do processo educacional, um papel que está sendo constituído (QUADROS, 2004, p. 60).

Nesta pesquisa, constatou-se que os docentes, talvez por falta de formação/informação adequada, deixaram a desejar no que se refere ao ato de ceder posição ao intérprete como, por exemplo, nos momentos das avaliações. Como já foi dito, os TILS precisam acompanhar os alunos, pois o material não thes é disponibilizado previamente para tradução.

Cada pessoa tem a sua função dentro da sala de aula. Se anteriormente havia dois atores nesse espaço (professor e aluno), surge agora um terceiro: o intérprete de Libras. De um lado, o aluno deverá ter clareza de quem é o intérprete e que este é apenas um intermediador da comunicação. Em tese, o tradutor não tem competência para esclarecer as dúvidas do aluno. Do outro lado, o professor deve estar ciente de que todos os alunos, surdos e ouvintes, são de fato seus alunos e que não pode dispensar a responsabilidade pedagógica ao intérprete.

São poucos os docentes que se enxergam como educadores de seus alunos surdos. Sejam os motivos relacionados à formação inicial e/ou continuada ou à identificação pessoal, uma série de questões que envolvem o ambiente escolar contribuem para que esta afirmativa aconteça. Uma amostra clara é a de transferir toda e qualquer forma de acessibilidade aos surdos para os intérpretes.

Há casos de um grande número de alunos dentro da sala de aula, chegando mesmo a ter turmas nas quais mais de $50 \%$ dos alunos são surdos. Esse fato acaba trazendo uma carga excessiva a um professor despreparado, tendo por consequência o distanciamento entre docente e discentes. Consequentemente, a responsabilidade de acompanhar o aluno recai sobre o intérprete. Este, por sua vez, não raro acaba assumindo tal responsabilidade. 


\section{RevistAleph}

Perante essas situações, surge um novo conflito: raramente o intérprete é formado para desempenhar seu papel e, quando formado, dificilmente é especialista na área na qual está atuando.

No tocante aos tradutores participantes desta pesquisa, $100 \%$ mostrou ter interesse de cursar uma graduação específica para sua profissão, enquanto $1 / 3$ está sendo pós-graduado em uma especialização em Libras. Esses dados mostram o quão difícil é encontrar um profissional qualificado para a atuação de áreas específicas.

Na educação, o intérprete de língua de sinais será altamente requisitado, uma vez que na grande parte do país, as escolas não são escolas para surdos. A atuação do intérprete em sala de aula será objeto de estudo de várias pesquisas, pois implicará em revisão constante de seu papel nos diferentes níveis de ensino (QUADROS, 2004, p. 82).

A presença dos surdos no cenário escolar traz atualmente alguns equívocos por parte dos profissionais envolvidos. Há relatos de que a falta de compreensão de como o intérprete atua em sala provoca em alguns professores desconforto e, em certos casos, desconfiança na sua competência profissional. Fomentando esta questão, há relatos por parte da comunidade surda de que muitos TILS não interpretam da forma correta, omitindo e acrescentando informações. Em complemento, os alunos afirmam que esses profissionais utilizam o horário em que deveriam estar atuando para conversarem sobre assuntos paralelos, soltando risadas e mantendo posturas que nutrem a falta de confiança de alguns professores.

Deve-se frisar, no entanto, que, em algumas situações, os próprios surdos, que usufruem das habilidades desses profissionais, tornam-se fiscalizadores do processo de tradução e interpretação, levando os problemas e os descontentamentos para a gestão escolar. Essa postura pode ser entendida mediante as observações de Bourdieu (1979, p.5), quando afirma que:

O habitus docente exerce uma violência simbólica no corpo discente de forma a legitimar os interesses e a cultura da classe dominante, que é julgada como a correta e que deve ser utilizada. Trata-se de algo que não é explícito, não é percebido por quem a sofre e nem por quem a exerce.

O descontentamento dos surdos torna-se bastante evidente quando se trata da utilização da língua portuguesa, a qual está presente em todo material didático usado, 


\section{RevistAleph}

sendo o idioma em que estão escritos os livros, os filmes, as atividades. O próprio Decreto no 5.626 assim afirma:

Art. 15. Para complementar o currículo da base nacional comum, o ensino de Libras e o ensino da modalidade escrita da Língua Portuguesa, como segunda língua para alunos surdos, devem ser ministrados em uma perspectiva dialógica, funcional e instrumental, como:

I. -atividades ou complementação curricular específica na educação infantil e anos iniciais do ensino fundamental;

II. - áreas de conhecimento, como disciplinas curriculares, nos anos finais do ensino fundamental, no ensino médio e na educação superior.

Decerto, o Brasil vive um processo histórico no campo educacional. A satisfação de ver pessoas que antes nem sequer chegavam ao ensino médio e hoje adentram em universidades de renome é uma vitória por parte da comunidade surda. Atualmente, os surdos estão muito mais conscientes e são protagonistas da própria trajetória de vida. Mas ainda há muito que fazer. É preciso que o princípio da alteridade seja praticado por todos os envolvidos com a comunidade surda (intérpretes, professores, gestores), como em um "mundo moral [...] que se estende entre eu e o Outro" (BAUMAN, 1997, p. 62).

Adquirir esta perspectiva de olhar para o Outro é dar oportunidade a toda comunidade escolar. De acordo com Marques (2008), é preciso (re)significar o olhar aos alunos. Em um ambiente carregado de pluralidades, mudar o significado dado historicamente há alunos com deficiência e àqueles discriminados pela sua condição financeira, de etnia, gênero, sexualidade, etc. trará benefícios na formação não só destes sujeitos, mas também aos demais. Assim, todos poderemos construir uma escola realmente inclusiva, acessível a todos.

Nessa perspectiva, Freire (1987) adverte os educadores sobre a necessidade de terem cuidado em não considerarem apenas os conteúdos, numa concepção bancária de ensino. O professor, assim como o intérprete, deve conhecer os sujeitos com quem está trabalhando. Por um lado, o professor deve estar sensível às diferenças que existem na classe, de forma que o conteúdo transmitido possa atingir e ser absorvido por todos os alunos. De outro lado, o intérprete deve procurar saber qual a forma de utilização da língua de sinais do aluno surdo para fazer as escolhas lexicais pertinentes no momento da interpretação. Assim, os três "atores" deste cenário escolar e inclusivo poderão "[...] 


\section{RevistAleph}

construir o conhecimento de forma satisfatória, num processo dialógico entre o professor, intérprete e o aluno." (PEREIRA, 2013, p. 94).

\section{Conclusão}

Intitular este trabalho com a palavra "bastidores" significou ir além do discutido no dia-a-dia da educação de surdos. Mesmo com um recorte pequeno, foi possível exemplificar muitos outros olhares sobre esta relação atual presente na nova configuração escolar.

Os objetivos traçados para a pesquisa foram alcançados quando ela trouxe à tona os laços existentes entre aluno surdo-professor-TILS, os quais surpreenderam fortemente mediante as hipóteses iniciais. Verificou-se que a aceitação unânime por salas de aula inclusivas, com a presença de TILS, pode ser um dado norteador e fomentador de novos projetos tanto em nível local como nacional.

A partir dessa análise, pode-se (re)pensar e (re)significar as práticas docentes, bem como dialogar e trocar saberes. Os dados aqui apresentados trouxeram a compreensão de que "[...] para a verdadeira escola inclusiva é necessária a transformação da concepção de deficiência vista pelos profissionais envolvidos. A ação deve ser baseada neste conceito." (BARTALOTTI, 2006, p. 57).

Deve-se ressaltar que aqui não há verdades absolutas, mas possibilidades, possibilidades estas que esperam novas atitudes das(os) novas(os) pedagogas(os). É possível, portanto, ir adiante, enfrentar, mobilizar o que estava engessado e realizar novas reflexões. Afinal, como diz Vanessa Vidal sobre os sujeitos surdos e sua principal característica - a língua:

[...] Pronunciar palavras eu posso, sim, converso com quem não sabe LIBRAS, normalmente. Mas no meu nome, na minha vida, na minha história, tenho como marca as minhas mãos, a minha forma de me comunicar: a LIBRAS! Esse bailado que sempre sugerirá benção, edificação. 'A mão é o verbo dos eleitos' [...] (VIDAL, 2011, p. 17).

\section{REFERÊNCIAS}

BARTALOTTI, C. C. Inclusão social das pessoas com deficiência. Utopia ou possibilidade? São Paulo: Paulus, 2006. 


\section{RevistAleph}

BAUMAN, Z. O Mal-Estar da Pós-Modernidade. Rio de Janeiro: Jorge Zahar, 1997.

BAUMAN, Z. Ética pós-moderna. São Paulo: Paulus, 1997.

BRASIL. Decreto no 5.626, de 22 de dezembro de 2005. Regulamenta a Lei no 10.436, de 24 de abril de 2002, que dispõe sobre a Língua Brasileira de Sinais - Libras, e o artigo 18 da Lei no 10.098, de 19 de dezembro de 2000. Disponível em:

http://www.planalto.gov.br/ccivil_03/_ato2004- 2006/2005/decreto/d5626.htm. Acesso em: 18 nov. 2018.

BRASIL. Lei no 10.436, de 24 de abril de 2002. Dispõe sobre a Língua Brasileira de sinais - Libras, e o artigo 18 da Lei no 10.098, de 19 de dezembro de 2000. Disponível em:

http://www.planalto.gov.br/ccivil_03/leis/2002/l10436.htm. Acesso em 12 ago. 2018.

BRASIL. Secretaria de Educação Especial - A educação dos Surdos (Org). Giuseppe Rinaldi et al. Brasília: MEC/SEESP, 1997.

BOURDIEU, Pierre. 0 desencantamento do mundo: estruturas econômicas e estruturas temporais. São Paulo: Perspectiva, 1979.

CARVALHO, E. de C.; BARBOSA, I. Pensamento Pedagógico e as NEE: Introdução à Deficiência Auditiva, [S.I], 2008.

FERNANDES, Sueli. Letramento na Educação Bilíngue para Surdos. IN: BERBERIAN, Ana Paula; MASSI Giselle; DE ANGELIS, Cristiane C. Mori (Org.). Letramento: referências em Saúde e Educação. São Paulo: Plexus, 2006.

FREIRE, P. Pedagogia do Oprimido. Rio de Janeiro: Paz e Terra, 1987.

GONÇALVES, Humberto Bueno; FESTA, Priscila Soares Vidal. Metodologia do Professor no Ensino de Alunos Surdos. Disponível em: www.opet.com.br/.../pdf/n6/ARTIGO-PRISCILA.pdf. Acesso em: 17 de outubro de 2018.

LACERDA, C. B. F. \& GÓES, M. C. R. (Org.). Surdez - Processos Educativos e Subjetividade. São Paulo: Lovise, 2000.

Marques, Rodrigo Rosso. A experiência de ser surdo: uma descrição fenomenológica. Tese (doutorado) - Universidade Federal de Santa Catarina, Centro de Ciências da Educação. Programa de Pós-Graduação em Educação. Santa Catarina, 2008.

MONTEIRO, M. S. História dos Movimentos dos Surdos e o Reconhecimento da Libras no Brasil. Disponível em: http://www.slideshare.nethistria--do-/asustecnologia/movimento-surdo-no- brasil. Acesso em: 18 nov. 2018.

MOURA, M. C. O Surdo. São Paulo: Revinter, 2000.

PEREIRA, Osmar Roberto. Alunos Surdos, Intérpretes de Libras e Professores: Atores em Contato na Universidade. Cadernos de Educação, v. 12, n. 24, p. 73-96, 2013. Disponível em: https://www.metodista.br/revistas/revistas-ims/index.php/cadernosdeeducacao/issue/view/296. Acesso em: 18 nov. 2018.

QUADROS, R. M.; MASUTTI, M. L. Codas Brasileiros: Libras e Português em Zonas de Contato. Estudos Surdos II. Petrópolis: Arara Azul, 2007, v. 1, p. 9-267.

QUADROS, R. 0 tradutor e intérprete de língua brasileira de sinais e língua portuguesa. Brasília: MEC/SEESP, 2004.

REILY, L. Escola Inclusiva: Linguagem e mediação. Campinas, SP: Papirus, 2004.

VIDAL, V. A verdadeira beleza: uma história de superação. 2. ed. Fortaleza: Expressão gráfica e editora Ltda., 2011.

Data do envio: 03/04/2019

Data do aceite: 03 /07/2019. 